ISSN 0103-8478

\title{
Morfologia de potros da raça Brasileiro de Hipismo
}

\author{
Morphology of Brasileiro de Hipismo foals
}

\author{
Fernanda Nascimento de Godoi ${ }^{{ }^{*}}$ José Aurélio Garcia Bergmann ${ }^{\mathrm{II}}$ Fernando Queiroz de Almeida \\ Dalinne Christian Carvalho dos Santos ${ }^{\text {II }}$ Ana Luisa Soares de MirandaII \\ Fernando de Oliveira Vasconcelos ${ }^{\text {II }}$ José Evandro Gervásio de Oliveira ${ }^{\text {II }}$ \\ Rodrigo Ramos Kaipper ${ }^{\text {III }}$ Agnaldo Machado Andrade ${ }^{\mathrm{I}}$
}

RESUMO

Objetivou-se avaliar a morfologia de potros da raça Brasileiro de Hipismo, utilizando análise de imagens digitais e medidas de perímetros corporais para estimativa de índices corporais dos animais. As mensurações lineares e angulares foram obtidas utilizando imagens digitais dos potros com câmera acionada pelo aplicativo Simi Reality Motion Systems ${ }^{\circledR}$. As medidas foram baseadas em pontos anatômicos realçados com 19 marcadores reflexivos. A análise estatística descritiva dos resultados foi realizada utilizando o programa SAS. Os potros estavam em crescimento, com aumento das medidas lineares de altura na cernelha e na garupa, comprimento do corpo, distância escápulo-metacarpofalângica e nos comprimentos do pescoço, da perna e do antebraço. Os ângulos úmero-radial, metacarpofalângico, fêmoro-tibial, tíbio-metatarsico aumentaram com a idade, enquanto que os ângulos da cabeça, do pescoço, coxofemoral, metatarso-falângico, escápulo-solo e coxo-solo foram variáveis entre os momentos de avaliação. Os potros foram classificados em mediolineos e hipermétricos pelos índices Corporal e Dáctilo-torácico, respectivamente. A avaliação do crescimento dos potros foi possivel através da imagem digital.

Palavras-chave: cavalos, conformação, hipismo, imagem digital, morfologia.

\section{ABSTRACT}

This research aimed to evaluate the morphology of Brasileiro de Hipismo foals using digital image analysis and girth measurements to estimate body indexes of animals. The linear and angular measurements were obtained by digital images of the foals with camera triggered by Simi Reality Motion Systems ${ }^{\circledast}$. The measures were based on anatomical landmarks highlighted with 19 reflective markers. A descriptive statistical analysis of the results was performed using the SAS program. The foals were growing, with increased linear measurements of height at withers and croup, body length, distance from shoulder-fetlock and neck length, leg length and forearm length. The angles humerus-radial, metacarpal-falangeano, femoro-tibial, tibio-metatarsal increased with age, whiles the angles of the head, neck, coxofemoral, metatarsal-falangeano, shoulder-floor and coxae-floor were variable among the periods. The foals were classified as medium shape and hypermetric by Corporal Index, Dactilo-thoracic Index, respectively. Assessment of growth of the foals was possible through a digital image.

Key words: conformation, equines, equestrian sports, digital image, morphology.

\section{INTRODUÇÃO}

Os equinos da raça Brasileiro de Hipismo possuem reconhecimento internacional, devido, principalmente, às vitórias conquistadas nas Olimpíadas de Atlanta, em 1996, em Sydney, em 2000, além das três medalhas de ouro por equipe nos Jogos Pan Americanos, em 2007, e da medalha de ouro nos Jogos Mundiais Militares, em 2011 (ABCCH, 2012). A Associação Brasileira de Criadores do Cavalo de Hipismo (ABCCH) participa da World Breeding for Sport Horses, que é a única associação internacional de livros genealógicos (Stud-Books) de equinos para o esporte e atua em conjunto com a Fédération Equestre Internationale (FEI).

\footnotetext{
IUniversidade Federal Rural do Rio de Janeiro (UFRRJ), 238970-970, Seropédica, RJ, Brasil. E-mail: fernandagodoi@gmail.com.

*Autor para correspondência.

"Escola de Veterinária (EV), Universidade Federal de Minas Gerais (UFMG), Belo Horizonte, MG, Brasil.

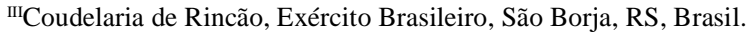


Segundo DIAS et al. (2000), os garanhões formadores da raça Brasileiro de Hipismo eram da raça Puro Sangue Inglês (20,9\%), Hanoverana $(16,1 \%)$, Westfalen $(10,5 \%)$, Holsteiner $(9,6 \%)$, Trakehner $(8,2 \%)$ e os machos da própria raça $(8,7 \%)$. Em relação às fêmeas, as denominadas "éguas-base" equivaleram a $42,8 \%$, que são matrizes nacionais com ou sem genealogia conhecida. As fêmeas da raça Puro Sangue Inglês foram equivalentes a $10,8 \%$ e éguas da própria raça foram equivalentes a $36,2 \%$.

$\mathrm{O}$ estudo de proporções e índices morfométricos auxilia nas verificações das aptidões dos equinos. $\mathrm{O}$ Índice Corporal relaciona $\mathrm{o}$ comprimento do corpo com o perímetro torácico dos equinos: $\mathrm{IC}=$ Comprimento do corpo $(\mathrm{cm}) /$ Perímetro torácico $(\mathrm{cm}) \times 100$, classificando-os em longelíneos, mediolíneos e brevilíneos. Os equinos longelíneos apresentam IC maior ou igual a 90; os mediolíneos com IC entre 86 e 89; e os brevilíneos com IC menor ou igual 85. O Índice Dáctilo-Torácico relaciona o perímetro da canela com o perímetro torácico e indica a correlação existente entre a massa dos equinos e os membros: $\mathrm{IDT}=$ Perímetro da canela $(\mathrm{cm}) /$ Perímetro torácico $(\mathrm{cm})$, classificando-os em hipermétricos, eumétricos e hipométricos. Os equinos hipermétricos apresentam IDT maior que 10,8; os eumétricos com IDT entre 10,8 e 10,5; e os hipométricos com IDT menor que 10,5. Segundo OOM \& FERREIRA (1987), esses valores foram encontrados por Marc e colaboradores em 1951, os quais correspondem a tipos distintos de equinos então existentes no Exército francês. TORRES \& JARDIM (1987) citam a classificação do Índice Dactilo-torácico um pouco diferente, em que o IDT não deve ser inferior a 10,5 nos equinos considerados leves; 10,8 nos intermediários; 11,0 nos de tração ligeira e 11,5 nos de tração pesada. $O$ índice de carga na canela (ICC) relaciona o perímetro da canela com o peso e indica a capacidade das extremidades em deslocar a massa do equino, sendo calculado com a fórmula: ICC $=$ Perímetro da canela $(\mathrm{cm}) /$ peso corporal $(\mathrm{kg}) \times 100$.

A avaliação morfométrica é importante e muito utilizada para a escolha de equinos, especialmente para atividades esportivas. Essas avaliações também podem ser utilizadas no estudo do crescimento desses animais e irão proporcionar a definição das taxas de crescimento específicas de cada raça. Nos equinos da raça Brasileiro de Hipismo, SANTOS et al. (1992) e MCMANUS et al. (2010) utilizaram medidas morfométricas da altura na cernelha, do perímetro torácico e o peso corpóreo para avaliar o crescimento dos potros até um ano de idade e até a idade adulta, respectivamente. SILVA (2006) destacou a importância da avaliação morfológica dos equinos participantes de competições de Concurso Completo de Equitação (CCE), verificando que os animais dessa modalidade não são selecionados pelo padrão racial, mas sim, pela morfologia, pois apenas o comprimento da cabeça diferiu significativamente entre machos e fêmeas, com valores de 65,71 e $64,93 \mathrm{~cm}$, nos equinos das raças Brasileiro de Hipismo, PSI e mestiços. Dessa forma, este trabalho teve como objetivo avaliar a morfologia de potros da raça Brasileiro de Hipismo, utilizando análise de imagens digitais e medidas de perímetros corporais para estimativa de índices corporais dos animais.

\section{MATERIAL E MÉTODOS}

Foram utilizados 109 potros da raça Brasileiro de Hipismo, de ambos os sexos, nascidos no período de setembro a dezembro de 2007, na Coudelaria de Rincão, Exército Brasileiro, São Borja, RS. Esses animais foram criados de maneira uniforme, em sistema extensivo, alimentados com $2 \mathrm{~kg}$ de concentrado comercial e $2 \mathrm{~kg}$ de aveia. $\mathrm{O}$ alimento volumoso foi fornecido como forrageiras nas pastagens.

As mensurações ocorreram em três momentos distintos, aos 22-25, aos 29-32 e aos 3639 meses de idade. As imagens bidimensionais foram obtidas com câmera Basler $A 602 f^{\circledR}{ }^{\circledast}$ posicionada num tripé a 16,3 metros dos animais e conectada por cabo firewire IEEE 1394 ao computador. A câmera foi acionada pelo aplicativo Simi Reality Motion Systems $^{\circledast}$ 4.7, 3D para a visualização, armazenamento e digitalização das imagens.

Foram fixados marcadores reflexivos com cinco centímetros de diâmetro em 19 regiões anatômicas, na face esquerda do corpo dos potros consideradas como referência para a avaliação das mensurações, segundo metodologia adaptada de CLAYTON \& SCHAMHARDT (2001). Os potros foram posicionados com os membros torácicos e pélvicos no plano perpendicular, formando um paralelogramo retangular, em picadeiro coberto, preparado com pano preto de $102 \mathrm{~m}^{2}$ ao fundo, no centro da área útil da filmagem e com dez holofotes de $500 \mathrm{~W}$, possibilitando melhor visualização dos marcadores reflexivos.

As medidas lineares foram: altura na cernelha - distância vertical do ponto mais alto da região interescapular, definido pelos processos espinhosos da $5^{\mathrm{a}}$ e da $6^{\mathrm{a}}$ vértebra torácica, ao solo; altura na garupa - distância vertical do ponto mais 
alto sobre a tuberosidade sacral ao solo; comprimento do corpo - distância linear entre a face cranial do tubérculo maior do úmero até a extremidade caudal da tuberosidade isquiática; comprimento do pescoço - distância linear entre a porção cranial da face lateral da asa do atlas e o ponto médio da borda cranial da escápula; distância espádua-boleto - distância da área central da articulação escápuloumeral até o terço médio da face da lateral da articulação metacarpofalângica do membro torácico esquerdo; comprimento do antebraço - distância da área central da articulação úmero-radial ao terço médio lateral da articulação cárpica; comprimento da canela torácica - distância do terço médio lateral da articulação cárpica ao terço médio da face lateral da articulação metacarpofalângica do membro torácico esquerdo; comprimento da quartela torácica distância do terço médio da face lateral da articulação metacarpofalângica à face lateral da articulação interfalângica proximal do membro torácico esquerdo; comprimento da perna - distância do ponto médio lateral da articulação fêmorotibial ao terço médio lateral da articulação társica; comprimento da canela pélvica - distância do terço médio lateral da articulação társica ao terço médio da face lateral da articulação metatarsofalângica do membro pélvico esquerdo; comprimento da quartela pélvica distância do terço médio da face lateral da articulação metatarsofalângica à face lateral da articulação interfalângica proximal do membro pélvico esquerdo, segundo descrição de PINTO et al. (2008) e, em acordo com a Nomenclatura Anatômica Veterinária Ilustrada (SCHALLER, 1999).

As medidas angulares foram definidas pela interseção de linhas baseadas em pontos anatômicos citados na figura 1: ângulo da cabeça - ângulo ventral formado pela interseção da linha entre a crista facial (1) e a asa do atlas (2) com a linha entre a asa do atlas (2) e a porção dorsal na cartilagem da escápula (3); ângulo do pescoço - ângulo ventral formado pela interseção da linha entre a asa do atlas (2) e a porção dorsal na cartilagem da escápula (3) com a linha entre este ponto e ao ponto da área central da articulação escápulo-umeral (5); espádua-braço - ângulo caudal formado pela interseção da linha entre a porção dorsal na cartilagem da escápula (3) e a área central da articulação escápulo-umeral (5) com a linha entre as áreas centrais das articulações escápulo-umeral (5) e úmero-radial (6); ângulo úmero-radial - ângulo cranial formado pela interseção da linha entre a área central da articulação escápulo-umeral (5) e a área central da articulação úmero-radial (6) com a linha entre a área central da articulação úmero-radial (6) e o terço médio lateral da articulação cárpica (7); ângulo metacarpo-falângico - ângulo cranial formado pela interseção da linha entre o terço médio lateral da articulação cárpica (7) e o ponto do terço médio da face lateral da articulação metacarpofalângica (8) com a linha entre o ponto do terço médio da face lateral da articulação metacarpofalângica (8) e a face lateral da articulação interfalângica proximal do membro torácico esquerdo (9); ângulo escápulosolo - ângulo caudal formado pela interseção da linha entre a porção dorsal na cartilagem da escápula (3) e a área central da articulação escápulo-umeral (5) com a linha do plano horizontal; ângulo coxo-solo - ângulo cranial formado pela interseção da linha entre o ponto médio ventral da face lateral da tuberosidade coxal (12) e a região média do trocânter maior do fêmur, na articulação coxo-femoral (13) com o plano horizontal; ângulo coxo-femoral - ângulo cranial formado pela interseção da linha entre a tuberosidade coxal (12) e a articulação coxo-femoral (13) com a linha entre a articulação coxo-femoral (13) e a articulação fêmorotibial (14); ângulo fêmoro-tibial - ângulo caudal formado pela interseção da linha entre a articulação coxo-femoral (13) e a articulação fêmoro-tibial (14) com a linha entre as articulações fêmoro-tibial (14) e társica (15); ângulo tíbio metatársico - ângulo cranial formado pela interseção da linha entre a articulação fêmoro-tibial (14) e a articulação társica (15) e a linha entre as articulações társica (15) com metatarsofalângica (16); ângulo metatarso-falângico ângulo cranial formado pela interseção da linha entre as articulações társica (15) e metatarsofalângica (16) e a linha entre as articulações metatarsofalângica (16) com a interfalângica proximal (17), segundo descrição de PINTO et al. (2008) e em acordo com a Nomenclatura Anatômica Veterinária Ilustrada (SCHALLER, 1999).

O peso corporal foi aferido com fita própria calibrada para estimativa do peso utilizando a mensuração do perímetro torácico. $\mathrm{O}$ perímetro torácico foi avaliado logo após a extremidade caudal da cernelha entre os processos espinhosos T8 e T9 até a articulação da $9^{\text {a }}$ costela com o processo xifóide. $\mathrm{O}$ perímetro do antebraço foi aferido medialmente entre a distância da área central da articulação úmeroradial ao terço médio lateral da articulação cárpica. $\mathrm{O}$ perímetro do joelho foi mensurado na região central do carpo e o perímetro da canela torácica foi avaliado na região medial entre a distância do terço médio lateral da articulação cárpica e o terço médio da face da lateral da articulação metacarpofalângica do membro torácico esquerdo (PINTO et al., 2008). 


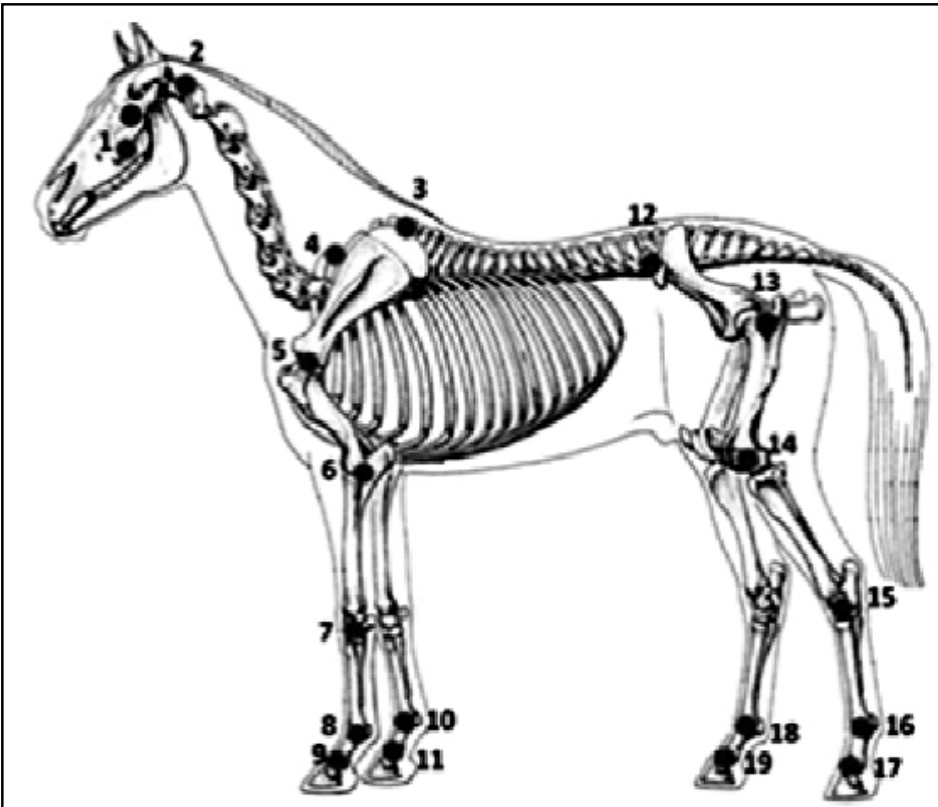

Figura 1 - Posicionamento dos marcadores reflexivos: 1) ponto médio da crista facial; 2) porção cranial da face lateral da asa do atlas; 3) porção dorsal na cartilagem da escápula seguindo a linha da espinha da escápula; 4) ponto médio da borda cranial da escápula, cranialmente ao músculo supra-espinhoso; 5) área central da articulação escápulo-umeral, na região da cavidade glenóide da escápula e cabeça do úmero; 6) área central da articulação úmero-radial, na região do côndilo do úmero, fóvea capitular do rádio e incisura troclear da ulna; 7) terço médio lateral da articulação cárpica, região lateral do osso carpiano ulnar; 8) terço médio da face lateral da articulação metacarpofalângica do membro torácico esquerdo; 9) face lateral da articulação interfalângica proximal do membro torácico esquerdo; 10) terço médio da face medial da articulação metacarpofalângica do membro torácico direito; 11) face medial da articulação interfalângica proximal do membro torácico direito; 12) ponto médio ventral da face lateral da tuberosidade coxal; 13) região média do trocanter maior do fêmur, na articulação coxofemoral; 14) ponto lateral da articulação fêmoro-tibial; 15) terço médio lateral da articulação társica, na região lateral entre a base do calcâneo e osso tálo; 16) terço médio da face lateral da articulação metatarsofalângica do membro pélvico esquerdo; 17) face lateral da articulação interfalângica proximal do membro pélvico esquerdo; 18) terço médio da face medial da articulação metatarsofalângica do membro pélvico direito e 19) face medial da articulação interfalângica proximal do membro pélvico direito; em acordo com a Nomenclatura Anatômica Veterinária Ilustrada (SCHALLER, 1999).

As mensurações foram utilizadas para estimativas de índices morfométricos: Corporal (IC), Dáctilo-torácico (IDT) e Carga na canela (ICC), que evidenciam relações existentes entre as medidas de comprimento, perímetro e peso, de acordo com OOM \& FERREIRA (1987) e CABRAL et al. (2004a).

Os resultados das mensurações foram submetidos à análise estatística descritiva utilizando o programa Statistical Analysis System.

\section{RESULTADOS E DISCUSSÃO}

Durante as avaliações, os potros ainda estavam em período de crescimento, como pode ser observado pelos valores crescentes da altura na cernelha, altura na garupa e nos comprimentos do corpo, do antebraço e da perna (Tabela 1 e 2). No período de avaliação, houve aumento médio de nove centímetros na altura na cernelha; oito centímetros 
Tabela 1 - Valores médios e desvio-padrão das medidas morfométricas lineares e angulares dos potros da raça Brasileiro de Hipismo, avaliados aos 22-25; 29-32 e 36-39 meses de idade.

\begin{tabular}{|c|c|c|c|}
\hline \multirow{2}{*}{ Variável } & \multicolumn{3}{|c|}{-Idade dos potros no momento da avaliação (meses) } \\
\hline & $22-25$ & $29-32$ & $36-39$ \\
\hline Altura na cernelha $(\mathrm{m})$ & $1,50+0,07$ & $1,57+0,07$ & $1,59+0,07$ \\
\hline Altura na garupa $(\mathrm{m})$ & $1,51+0,08$ & $1,57+0,07$ & $1,59+0,08$ \\
\hline Comprimento do pescoço $(\mathrm{m})$ & $0,59+0,04$ & $0,63-0,04$ & $0,64+0,05$ \\
\hline Distància escápula-boleto (m) & $0,93+0,04$ & $0,98+0,05$ & $0,98+0,06$ \\
\hline Comprimento do antebraço (m) & $0,42+0,03$ & $0,43-0,02$ & $0,44 \pm 0,03$ \\
\hline Comprimento da canela torácica $(\mathrm{m})$ & $0,30 \pm 0,02$ & $0,30=0,02$ & $0,30 \pm 0,02$ \\
\hline Comprimento quartela torácica (m) & $0,12+0,01$ & $0,12+0,01$ & $0,12+0,01$ \\
\hline Comprimento da perna $(\mathrm{m})$ & $0,49+0,05$ & $0,53-0,04$ & $0,54+0,04$ \\
\hline Comprimento da canela pélvica (m) & $0,37 \pm 0,03$ & $0,37-0,02$ & $0,37+0,02$ \\
\hline Comprimento da quartela pélvica (m) & $0,12+0,01$ & $0,12+0,01$ & $0,12+0,01$ \\
\hline Ângulo da cabeça $\left({ }^{\circ}\right)$ & $71,9 \pm 7,11$ & $72,5 \pm 6,14$ & $70,0 \pm 5,20$ \\
\hline Ângulo do pescoço $\left({ }^{\circ}\right)$ & $86,2+6,85$ & $88,6+6,33$ & $87,8+6,62$ \\
\hline Ângulo escápulo-umeral $\left({ }^{\circ}\right)$ & $108,5+6,49$ & $108,5+5,80$ & $107,2+4,84$ \\
\hline Ângulo úmero-radial $\left({ }^{\circ}\right)$ & $146,3+6,24$ & $145,7+5,75$ & $144,0+5,16$ \\
\hline Ângulo metacarpo-falângico $\left({ }^{\circ}\right)$ & $131,9+5,94$ & $140,1+6,36$ & $139,4+6,76$ \\
\hline Ângulo coxo-femoral $\left({ }^{\circ}\right)$ & $79,3+7,69$ & $85,1+7,19$ & $83,2+8,77$ \\
\hline Ângulo fêmoro-tibial $\left({ }^{\circ}\right)$ & $115,6=8,61$ & $122,5 \pm 8,32$ & $120,7 \pm 7,86$ \\
\hline Ângulo tíbio-metatársico $\left(^{\circ}\right)$ & $152,8=4,31$ & $154,2 \pm 3,43$ & $155,5 \pm 3,66$ \\
\hline Ângulo metatarso-falângico $\left({ }^{\circ}\right)$ & $138,9+5,89$ & $145,7+5,80$ & $142,8+7,11$ \\
\hline Ângulo escápulo-solo $\left({ }^{\circ}\right)$ & $59,0+3,83$ & $58,7+3,83$ & $59,7+4,33$ \\
\hline Ângulo coxo-solo $\left({ }^{\circ}\right)$ & $22,9+4,33$ & $25,6+4,75$ & $24,4-5,17$ \\
\hline
\end{tabular}

na altura na garupa e no comprimento do corpo; cinco centímetros na distância escápula-boleto e nos comprimentos do pescoço e da perna; e dois centímetros no comprimento do antebraço. Enquanto que os comprimentos da canela e da quartela dos membros torácico e pélvico não apresentaram alterações no período de avaliação. $\mathrm{O}$ comprimento da canela do membro pélvico apresentou-se sete centímetros maior, em média, em relação ao comprimento da canela torácica. Os comprimentos das quartelas do membro torácico e pélvico foram semelhantes, de $12 \mathrm{~cm}$. Os potros apresentaram valores semelhantes de alturas na cernelha e na garupa, exceto no primeiro momento de avaliação, aos 22-25 meses de idade, quando a altura na garupa apresentou um centímetro maior que a altura na cernelha.

Os valores dos ângulos úmero-radial, metacarpo-falângico, fêmoro-tibial, tíbio-metatársico aumentaram com o aumento da idade, indicando abertura dos ângulos. Porém, foi observado que os ângulos da cabeça, do pescoço, coxo-femoral, metatarso-falângico, escápulo-solo e coxo-solo apresentaram variações nos valores entre os momentos de avaliação, ora com aumento, ora com redução das angulações. As variações nos valores dos ângulos também foram observadas em estudos com potros da raça Mangalarga Marchador, utilizando o artrogoniômetro (CABRAL et al., 2004b), o que pode ser atribuído ao crescimento corporal.

A instabilidade de todas as características mensuradas no presente trabalho representada pelo coeficiente de variação (CV) foi de 2,23 a 21,19\%, sendo o menor valor observado para o ângulo tíbiometatársico, no segundo momento de avaliação, e o maior valor para o ângulo coxo-solo no terceiro momento de avaliação. Os valores observados do CV são bastante inferiores aos valores indicados como limite máximo recomendado para experimentos com animais, de 20 a 30\% (SAMPAIO, 2002). PINTO et al. (2008) observaram coeficientes de variação entre 1,83 a $18,18 \%$ nas medidas lineares e angulares de equinos da raça Mangalarga Marchador, utilizando hipômetro e artrogoniômetro.

O ângulo escápulo-umeral apresentou menor valor com os potros na idade de 36-39 meses, de $107,2^{\circ}$. Esse ângulo é importante para equinos com aptidão para o salto, pois influencia na báscula do pescoço e no recolhimento dos membros torácicos durante o salto de obstáculo e a absorção do impacto durante a aterrissagem, uma vez que as partes anatômicas envolvidas estão diretamente conectadas. 
Tabela 2 - Valores médios e desvio-padrão dos Índices Corporal, Dáctilo-Torácico e Carga na Canela e das medidas utilizadas para estimativas dos índices nos potros da raça Brasileiro de Hipismo.

\begin{tabular}{|c|c|c|c|}
\hline \multirow{2}{*}{ Variável } & \multicolumn{3}{|c|}{-Idade dos potros no momento da avaliação (meses)--- } \\
\hline & $22-25$ & $29-32$ & $36-39$ \\
\hline Peso corporal (kg) & $412,00+38,84$ & $461,00+39,61$ & $461,00+33,17$ \\
\hline Comprimento do corpo $(\mathrm{m})$ & $1,54+0,09$ & $1,62+0,07$ & $1,62+0,09$ \\
\hline Perímetro torácico $(\mathrm{m})$ & $1,74+0,06$ & $1,82+0,06$ & $1,82+0,05$ \\
\hline Perímetro do antebraço $(\mathrm{cm})$ & $34,00+1,83$ & $35,00+2,17$ & $36,00+2,06$ \\
\hline Perímetro da canela torácica $(\mathrm{cm})$ & $20,00-0,99$ & $21,00+0,99$ & $22,00+1,19$ \\
\hline Perímetro do joelho $(\mathrm{cm})$ & $33,00 \pm 1,70$ & $34,00 \pm 1,73$ & $34,00 \pm 1,99$ \\
\hline Índice Corporal (IC) & $88,57 \pm 4,36$ & $89,52 \pm 3,94$ & $88,04 \pm 4,73$ \\
\hline Índice Dáctilo-Torácico (IDT) & $11,80+0,49$ & $11,41+0,48$ & $11,98-0,57$ \\
\hline Índice Carga na Canela (ICC) & $5,05+0,35$ & $4,56+0,35$ & $5,30+0,31$ \\
\hline
\end{tabular}

SILVA (2009), avaliando potros da raça Brasileiro de Hipismo aos quatro anos de idade, oriundos do mesmo criatório, também verificou a importância da angulação escápulo-umeral ao constatar que foi a única variável angular que apresentou diferença significativa entre os grupos de equinos considerados melhores e piores saltadores, com valores de 92,17 e $95,75^{\circ}$, respectivamente. SCHLUP (2010), avaliando equinos da raça Brasileiro de Hipismo antes e após cinco meses de treinamento na modalidade de salto, verificou que a angulação escápulo-umeral foi a variável mais influenciada pelo treinamento. TORRES \& JARDIM (1987) citam que o menor ângulo escápulo-umeral favorece amplitude dos movimentos, porém o membro torácico não se eleva muito, enquanto o maior valor desse ângulo é favorável a andamentos menos alongados, porém fortes e altos.

$\mathrm{Na}$ raça Brasileiro de Hipismo, o julgamento para aprovação de garanhões ocorre aos cinco anos de idade, seguindo um sistema de pontuação comparativo de cada animal com o protótipo ideal do moderno cavalo de hipismo (pontuação 10). Também há o emprego de medidas morfológicas utilizando instrumentos manuais, como altura na cernelha, perímetro torácico e perímetro da canela, assim como análise visual da locomoção e do salto de obstáculos (ABCCH, 2012).

Os índices foram calculados e os potros classificados em mediolíneos e hipermétricos, respectivamente, pelos índices Corporal e Dáctilotorácico. O Índice Corporal apresentou baixa variação entre os momentos de avaliação, de 88,04 a 89,59. O Índice Dáctilo-Torácico também apresentou pouca variação entre os momentos de avaliação, de 11,41 a 11,98 (Tabela 2). Em outras raças de equinos, a
Pantaneira e a Campeira, o Índice Dáctilo-Torácico foi de 10,5 e 10,9 , respectivamente, indicando similaridade no potencial de uso dessas duas raças, que são intermediárias entre sela e tração leve. Em equinos da raça Mangalarga Marchador, animais tipo sela, os valores foram de 10,90 e 10,83, nos machos e fêmeas, respectivamente, classificando-os como eumétricos. Em equinos da raça Alter, o IDT foi de 10,80 e 10,19, nos machos e nas fêmeas adultos, classificando-os como eumétricos e hipométricos, respectivamente (OOM \& FERREIRA, 1987; MISERANI et al., 2002; CABRAL et al., 2004a; McMANUS et al., 2005).

$\mathrm{Na}$ avaliação da relação entre a altura na cernelha e o comprimento corporal, verificou-se que, em todos os momentos de avaliação, os potros são ligeiramente mais compridos que altos, com valores dessa relação de $0,97 \pm 0,10 ; 0,97 \pm 0,03$ e $0,98 \pm 0,03$ quando os animais apresentavam 22-25; 29-32 e 3639 meses de idade, respectivamente.

O índice de carga na canela aumentou com a idade, de 5,05 aos 22-25 meses de idade e, de 5,30 aos 36-39 meses de idade, pois os potros haviam aumentado de peso. OOM \& FERREIRA (1987) citam que valores muito baixos de ICC correspondem a equinos com membros fracos, eventualmente insuficientes para se locomoverem com eficácia, comprometendo a aptidão motriz para qualquer utilização. Esses autores observaram que as fêmeas da raça Alter apresentam valores mais baixos de ICC que os machos, denotando membros mais fracos para o respectivo peso, de 3,89 nos machos e de 3,63 nas fêmeas. Em equinos da raça Mangalarga Marchador, foi observado ICC de 26,18 ao nascimento até 4,16 na idade adulta, essa variação é explicada pelo ganho de massa corporal, em contraposição à pequena 
variação do perímetro da canela (CABRAL et al., 2004a). Neste trabalho, os perímetros do antebraço e da canela aumentaram um centímetro em cada avaliação, porém os perímetros torácicos e do joelho aumentaram somente até 29-32 meses de idade.

O conhecimento das medidas morfométricas dos potros se faz necessário para acompanhar o desenvolvimento desses animais, visando evitar o sub ou o super crescimento e ganhos compensatórios. O uso de câmera digital e os programas de análise digital mostraram-se eficientes ferramentas na avaliação de potros, sendo necessários apenas alguns segundos com o potro em estação forçada para que se realizassem todas as mensurações com precisão.

\section{CONCLUSÃO}

Os potros da raça Brasileiro de Hipismo, dos 22 aos 39 meses de idade, apresentaram maior desenvolvimento nas medidas lineares da altura na cernelha, altura na garupa e comprimento do corpo, com a possibilidade da avaliação do crescimento através da imagem digital, sendo classificados em animais mediolíneos e hipermétricos pelos Índices Corporal e Dáctilo-torácico, respectivamente.

\section{COMITÊ DE ÉTICA}

Pesquisa registrada no Comitê de Ética em Experimentação Animal da UFMG: 267/08.

\section{REFERÊNCIAS}

ASSOCIAÇÃO BRASILEIRA DE CRIADORES DO CAVALO DE HIPISMO. Disponível em: <http://www.brasileirodehipismo. com.br/upload/arquivos/REGULAMENTO_STUDBOOK_ FINAL_2011.pdf>. Acesso em: Acesso em: 14 abr. 2012.

CABRAL, G.C. et al. Avaliação morfométrica de equinos da raça Mangalarga Marchador: índices de conformação e proporções corporais. Revista Brasileira de Zootecnia, v.33, n.6, p.1798-1805, 2004a. Disponível em: <http://www.scielo. br/scielo.php? $\mathrm{pid}=\mathrm{S} 1516-35982004000700018 \&$ script $=\mathrm{sci}_{-}$ abstract\&tlng=es>. Acesso em: 14 abr. 2012. doi: 10.1590/S151635982004000700018 .

CABRAL, G.C. et al. Avaliação morfométrica de equinos da raça Mangalarga Marchador: medidas angulares. Revista Brasileira de Zootecnia, v.33, n.4, p.989-1000, 2004b. Disponível em: <http://www.scielo.br/scielo.php?script=sci_ arttext\&pid=S1516-35982004 000700017 $>$. Acesso em: 14 abr. 2012. doi: 10.1590/S1516-35982004000700017.

CLAYTON, H.M.; SCHAMHARDT, H.C. Measurement techniques for gait analysis. In: BACK, W; CLAYTON, H.M. Equine locomotion. Philadelphia: Saunders, 2001. p.55-76.
DIAS, I.M.G. et al. Formação e estrutura populacional do equino Brasileiro de Hipismo. Arquivo Brasileiro de Medicina Veterinária e Zootecnia, v.52, n.6, p.647-654, 2000. Disponível em: <http://www.scielo.br/scielo. php?script=sci_arttext\&pid=S0102-09352000000600016>. Acesso em: 14 abr. 2012. doi: 10.1590/S0102-09352000000600016.

McMANUS, C. et al. Caracterização morfológica de equinos da raça campeiro. Revista Brasileira de Zootecnia, v.34, n.5, p.1553-1562, 2005. Disponível em: <http://www.scielo.br/pdf/rbz/ v34n5/26635.pdf>. Acesso em: 27 set. 2012. doi: 10.1590/S151635982005000500015 .

McMANUS, C.M. et al. Non linear growth curves for weight and height in four genetic groups of horses. Ciência Animal Brasileira, v.11, p.80-89, 2010. Disponível em: <http://www.revistas.ufg.br/ index.php/vet/article/view/5400/8062>. Acesso em: 27 set. 2012. doi: 10.5216/cab.v11i1.5400.

MISERANI, M.G. et al. Avaliação dos fatores que influem nas medidas lineares do cavalo pantaneiro. Revista Brasileira de Zootecnia, v.31,n.1, p.335-341,2002. Disponívelem: <http://www. scielo.br/scielo.php?pid=s1516-35982002000200007\&script=sci arttext>. Acesso em: 27 set. 2012. doi: 10.1590/S151635982002000200007 .

OOM, M.M.; FERREIRA, J.C. Estudo biométrico do cavalo Alter Revista Portuguesa de Ciências Veterinárias, v.83, n.482, p.101148, 1987.

PINTO, L.F.B. et al. Evaluation of the sexual dimorphism in Mangalarga Marchador horses using discriminant analysis. Livestock Science, v.119, p.161-166, 2008. Disponível em: <http:// www.sciencedirect.com/science/article/pii/S187114130800098X>. Acesso em: 14 abr. 2012. doi:10.1016/j.livsci.2008.03.014.

SAMPAIO, I.B.M. Estatística aplicada à experimentação animal. 2.ed. Belo Horizonte: FEPMVZ, 2002. 265p.

SANTOS, S.A. et al. Influência de alguns fatores ambientais sobre características de crescimento de cavalos Brasileiro de Hipismo até um ano de idade. Pesquisa Agropecuária Brasileira, v.27, n.1, p.171-179, 1992. Disponível em: <https://seer.sct.embrapa. br/index.php/pab/article/view/3632>. Acesso em: 27 de set. 2012.

SCHALLER, O. Nomenclatura anatômica veterinária ilustrada. São Paulo: Manole, 1999. 560p.

SCHLUP, E. Cinemática do salto de equinos de iniciação esportiva na Escola de Equitação do Exército. 2010. 55f Dissertação (Mestrado em Zootecnia) - Universidade Federal Rural do Rio de Janeiro, RJ.

SILVA, C.E.L.A. Parâmetros morfológicos de equinos novos em estação e durante o salto na Escola de Equitação do Exército 2009. 58 f. Monografia (Especialização em Instrutor de Equitação) - Escola de Equitação do Exército, Rio de Janeiro, RJ.

SILVA, E.G.A. Avaliação morfométrica e do desempenho de cavalos de Concurso Completo de Equitação. 2006. 100f. Dissertação (Mestrado em Medicina Veterinária) - Escola de Veterinária, Universidade Federal de Minas Gerais, MG.

TORRES, A.P.; JARDIM, W.R. Criação do cavalo e de outros equinos. 3.ed. São Paulo: Nobel, 1987. 654p. 